\title{
Comparative Evaluation of the Bladder Tumor-Associated Antigen, Urinary Bladder Cancer Antigen, Tissue Polypeptide Specific Antigen and Voided Urine Cytology in Early Detection of Primary Bladder Tumors
}

\author{
ADINA ELENA STANCIU ${ }^{1 \#, ~ N A F I J A ~ S E R D A R E V I C ~}{ }^{2}$, MARCEL MARIAN STANCIU ${ }^{3, *}$, LAURA MAZILU ${ }^{4}$, \\ OVIDIU BRATU ${ }^{5}$, MIRELA GHERGHE ${ }^{5 \#}$, SILVIU CRISTIAN VOINEA ${ }^{\text {5\# }}$, DAN CRISTIAN GHEORGHE \\ ${ }^{1}$ Institute of Oncology Bucharest, Department of Carcinogenesis and Molecular Biology, 252 Fundeni, 022338, Bucharest, \\ Romania \\ ${ }^{2}$ Institute for Clinical Chemistry and Biochemistry, University of Sarajevo Clinics Center, Bolnicka 25, 71000, Sarajevo, \\ Bosnia and Herzegovina \\ ${ }^{3}$ University Politehnica of Bucharest, Electrical Engineering Faculty, 313 Splaiul Independentei, 060042, Bucharest, \\ Romania \\ ${ }^{4}$ University Ovidius Constanța, Faculty of Medicine, 124 Mamaia Str., 900527, Constanța, Romania \\ ${ }^{5}$ Carol Davila University of Medicine and Pharmacy, 8 Eroii Sanitari, 050474, Bucharest, Romania
}

\begin{abstract}
Although a large number of biomarkers for primary assessment of non-muscle-invasive bladder cancer (NMIBC) have been explored, their real diagnostic performance is not well known. This study aimed to conduct a direct comparison of three biomarkers [bladder tumor-associated antigen (BTA), urinary bladder cancer antigen (UBC) and tissue polypeptide specific antigen (TPS)] with some unique characteristics for detection of NMIBC and to compare their diagnostic accuracy to that of routine urine cytology. Our results indicated that the overall clinical sensitivity of BTA was the highest of all assays (76.92\%), whereas that of cytology was the smallest one (12.50\%). On the other hand, BTA and cytology had the highest specificities (89.79\% vs. $96.87 \%)$ with no significant differences between them. A multi-biomarker panel including BTA, UBC, and TPS with an overall clinical specificity of $100 \%$ better assess the primary NMIBC as compared to approaches entailing just one or two of these biomarkers or routine urine cytology.
\end{abstract}

Keywords: BTA, UBC, TPS, urinary cytology, bladder cancer

Bladder cancer (BC), the tenth most common form of cancer worldwide, occurs more often in men (the second most common genitourinary cancer after the prostate cancer) than in women [1]. Several prospective studies [2-4] have reported an association of elevated blood glucose levels with increased overall cancer incidence, including BC. Another risk factors are tobacco smoking, workplace exposures, obesity, dietary supplements containing aristolochic acid and glucose-lowering drugs like pioglitazone or insulin [5]. Because, there is not yet a sufficiently precise test to screen the general population for $\mathrm{BC}$, most people are diagnosed with this disease only after the onset of symptoms (gross hematuria, dysuria, nocturia, frequency of urination, or urinary urgency), $85 \%$ of patients having at presentation non-muscle-invasive bladder cancer (NMIBC), consisting of Ta (urothelial papillary tumors - 70\%), T1 (tumor invades subepithelial connective tissue - 20\%) and carcinoma in situ CIS or Tis (flat erythematous lesions - 10\%) [6]. Unlike other cancers, BC is an insidious disease showing a high rate of recurrence (50-70\% within five years), often in association with more aggressive and invasive tumors, requiring examination of patients at frequent intervals [7, 8]. Combination of cystoscopy and urine cytology is considered the "gold standard" in the diagnostic assessment of patients with suspicion for BC, as well as for the detection of early recurrences during the follow-up of the bladder tumors. Despite the benefits it shows, cystoscopy is an invasive technique that causes discomfort and side effects including infections. Regarding urine cytology, its utility is limited by its reduced sensitivity, particularly for low grade (well-differentiated) tumors. In an attempt to improve the diagnosis and monitoring of patients with BC, mainly for NMIBC group, in which cystoscopy and cytology are challenging to interpret due to their low sensitivity, several non-invasive biomarkers have been developed. In the present study, three biomarkers with some unique characteristics [bladder tumor-associated antigen (BTA), urinary bladder cancer antigen (UBC) and tissue polypeptide specific antigen (TPS)] has been selected.

\footnotetext{
*email: marcel.stanciu@upb.roPhone: (+40) 728-699-093
}

All this authors contributed equally to the present work 
The BTA TRAK assay test measures the urinary level of BTA [human complement factor $\mathrm{H}$ related protein (hCFHrp)]. It has been shown that hCFHrp is similar in structure and function to human complement factor $\mathrm{H}$ (hCFH) [9], allowing the BC cells to evade the host immune system and to grow up [10,11]. Cytokeratins are intracellular proteins in the intracytoplasmic cytoskeleton of epithelial cells, their expression being dependent on the embryonic development and degree of cellular differentiation [12]. UBC assay test measures soluble fragments of cytokeratin 8 and 18 which are derived from dead urinary BC cells in urine supernatant $[11,13,14]$ and TPS soluble fragments of cytokeratin 18 in blood [12].

This study was designed to measure the urinary BTA, UBC, and serum TPS concentrations and to compare their diagnostic performance to that of routine urine cytology for primary NMIBC.

\section{Experimental part}

Materials and methods

This work enrolled 124 patients $(98 \mathrm{M} / 26 \mathrm{~F}$, age $59 \pm 7$ years) recruited from the Institute of Oncology Bucharest and Fundeni Clinical Institute. All patients underwent cystoscopy as a reference standard for detection of BC, and all tumors or suspicious lesions were resected. The final diagnosis of NMIBC was based on histological examination [6]. The patients were divided into two groups: NMIBC group (55 patients) and benign bladder lesions group (69 patients). The tumor stages of $\mathrm{BC}$ patients were defined according to the Union for International Cancer Control (UICC) TNM classification (8th edition) $[15,16]$. For each enrolled subject, a detailed medical (tobacco smoking, working in a toxic environment, associated pathologies) and drug history was obtained.

Seventy healthy age- and gender-matched subjects $(55 \mathrm{M} / 15 \mathrm{~F}$, age $58 \pm 9$ years) were randomly selected from the individuals who volunteered for general routine health evaluation.

The study conformed to the principles outlined in the Declaration of Helsinki and was approved by the ethics committees of the respective institutes (Institute of Oncology Bucharest and Fundeni Clinical Institute). Enrolled patients and volunteers signed informed consent.

\section{Biomarker measurements}

Fresh voided urine samples were collected in clean urine cups before cystoscopy and divided as follows: a portion was taken for routine urine cytology, and the remaining part was centrifuged at $1000 \mathrm{x} g$ for 10 minutes, the supernatant being immediately aliquoted into labeled cryo-vials and stored at $-70^{\circ} \mathrm{C}$ for BTA TRAK and UBC assay tests.

Fasting blood samples were collected before cystoscopy by venipuncture into Vacutainer (Becton Dickinson, Rutherford, NJ, USA) serum separation tubes $(6 \mathrm{~mL})$. The serum samples were obtained by centrifugation at $3000 \times \mathrm{g}$ for 15 min after 30 min of clotting time at room temperature. Strongly lipemic or hemolyzed samples were removed from the study. Serum samples were then immediately aliquoted and stored at $-70{ }^{\circ} \mathrm{C}$ for TPS assay test.

Urinary (BTA, UBC), and serum (TPS) concentrations were measured using commercially available quantitative enzyme-linked immunosorbent assay (ELISA) kits (BTA TRAK from Polimedco Inc.; UBC and TPS from IDL Biotech). The precision (intra-assay variation) was tested by eight measurements of three different samples of known concentrations in one assay. The reproducibility (inter-assay variation) for the same three specimens was tested eight times in two assays. The values of the inter-assay imprecision study were similar to those from the intra-assay study with CVs ranging from 1.5 to $4.3 \%$. All tests were performed in duplicate according to the manufacturers' recommendations and in such a way to minimize any effects of repeated freeze-thaw cycles.

\section{Statistical analysis}

Statistical analysis was performed with Statistica 8.0 and Origins software. Qualitative data were described using numbers and percents. Because quantitative data were not Gaussian distributed (Kolmogorov-Smirnov test), they were presented as median [interquartile range (IQR) $25-75 \%$ ]. The following diagnostic indicators of NMIBC were used to assess the diagnostic performance of biomarkers: sensitivity (true-positive rate), specificity (true-negative rate), positive predictive value (PPV: probability that the patients with a positive test truly have NMIBC), negative predictive value (NPV: probability that the patients with a negative test truly do not have NMIBC), diagnostic effectiveness or accuracy (proportion of correctly classified patients among all patients) and area under the receiver-operating characteristic (ROC) curve, cystoscopy and histological evaluation being the reference standards. The total area under the ROC curve (AUC) is an overall summary of diagnostic accuracy as follows: AUC $>0.9$ excellent diagnostic accuracy; AUC between 0.7 and 0.9 good diagnostic accuracy; AUC between 0.5 and 0.7 poor diagnostic accuracy; AUC $<0.5$ the lack of diagnostic value of the biomarker. Cut-off values for optimal sensitivity and specificity have been determined by ROC curves. For all tests a P-value $<0.05$ was considered to be statistically significant. 


\section{Results and discussions}

Identifying the "optimal" panel of biomarkers for assessing primary NMIBC remains a challenging task. The rationale behind the selection of the three biomarkers was to alleviate the potential interferences that might occur when measuring BTA and UBC from voided urine samples. Because urinary BTA and UBC levels can be increased as a result of a benign condition (urinary tract infection, urolithiasis, prostatitis, etc.) [9, 10], we decided to select another biomarker that can be measured from the blood. The primary goal of this study was to define better the potential roles of the three biomarkers (BTA, UBC, TPS) in the initial assessment of NMIBC, their concentrations in the three study groups (NMIBC and benign bladder lesions groups of patients and healthy control group) being presented in Table 1. In the NMIBC group, the urinary concentrations of BTA, UBC and serum concentrations of TPS were higher compared to those measured in the benign bladder lesions group of patients or healthy controls, with statistical significance only for BTA and TPS (all P $<0.001$ ). Our results are consistent with the previous studies $[9,10,11,13]$ showing elevated BTA and UBC concentrations in BC patients compared to benign bladder lesions patients and healthy controls. In contrast to our study, Halim et al. [17] found no significant differences in the serum TPS levels between malignant and non-malignant bladder tumors.

Table 1

BIOMARKERS CONCENTRATIONS IN THE THREE STUDY GROUPS

\begin{tabular}{|c|c|c|c|}
\hline \multirow{2}{*}{ Variables } & NMIBC Group & Benign Group & Healthy Control Group \\
\cline { 2 - 4 } & $\mathrm{n}=55$ & $\mathrm{n}=69$ & $\mathrm{n}=70$ \\
\hline BTA $(\mathbf{I U} / \mathbf{m L})^{\mathbf{a}}$ & $87.9(18.7-450.0)$ & $4.3(2.3-7.1)$ & $2.8(1.2-7.4)$ \\
\hline UBC $(\mathbf{n g} / \mathbf{m L})^{\mathbf{a}}$ & $7.2(4.7-14.1)$ & $5.5(3.8-8.1)$ & $34.4(1.1-7.5)$ \\
\hline TPS $(\mathbf{I U} / \mathbf{L})^{\mathbf{a}}$ & $96.6(24.9-134)$ & $55.1(28.7-105.1)$ & $(19.0-56.2)$ \\
\hline \multicolumn{2}{|c|}{ NMIBC, non-muscle-invasive bladder cancer } \\
\hline
\end{tabular}

A secondary endpoint of this study was to compare the diagnostic performance of BTA, UBC, TPS, and cytology of voided urines. The cut-off values determined by ROC curves were as follows: $15.4 \mathrm{IU} / \mathrm{mL}$ for BTA, $12.9 \mathrm{ng} / \mathrm{mL}$ for UBC and 57.7 IU/L for TPS (Figure 1).

AUC can range from 0.5 to 1 , the values close to 1 indicating high discriminatory ability. As shown in Figure 1 , the largest AUC was for BTA (0.913), and then UBC (0.650) and TPS (0.568), BTA demonstrating an excellent diagnostic accuracy for low-grade and early-stage disease in BC patients.

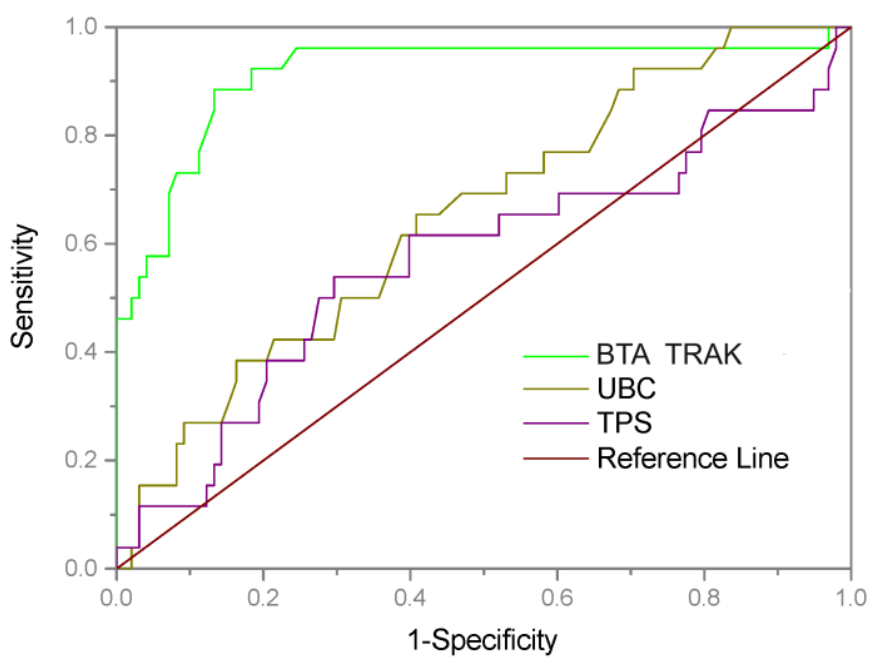

Fig. 1. ROC curves of BTA, UBC, and TPS tests for patients presenting with signs, symptoms, or diagnostic results suggestive of bladder cancer

As opposed to Priolo et al. [18] who found that cytology was diagnostically better than BTA for an optimal cut-off of $34 \mathrm{IU} / \mathrm{mL}$ (sensitivity: $68.3 \%$ vs. $63 \%$; specificity: $73.4 \%$ vs. $71 \%$ ), the present study revealed that BTA was a more effective diagnostic test than cytology for an optimal cut-off of $15.4 \mathrm{IU} / \mathrm{mL}$, BTA having the highest AUC, overall clinical sensitivity and diagnostic accuracy (Figure 1 and Table 2) of all analyzed assays. In contrast to its rather low sensitivity, cytology exhibited excellent specificity (96.87\%), without statistically significant differences compared to the other tests (BTA: 89.79\%; UBC: $86.73 \%$ and TPS: 54.08\%). In line with our results, several reports $[11,13,14,19,20]$ showed that 
compared to urine cytology, UBC alone revealed higher sensitivity in detecting low-grade bladder tumors and lower specificity. As for TPS, we have not found studies that analyze its diagnostic performance for prediction of NMIBC. Our study showed that TPS was significantly more sensitive and less specific than voided urine cytology and UBC $(\mathrm{P}<0.001$ for both comparisons).

Table 2

COMPARISON BETWEEN THE DIAGNOSTIC PERFORMANCE OF BTA, UBC, TPS, AND URINE CYTOLOGY

\begin{tabular}{|c|c|c|c|c|c|}
\hline Variable & Sensitivity(\%) & Specificity(\%) & PPV(\%) & NPV(\%) & Accuracy(\%) \\
\hline BTA & 76.92 & 89.79 & 93.61 & 66.66 & 87.09 \\
\hline UBC & 26.92 & 86.73 & 81.73 & 35 & 74.19 \\
\hline TPS & 61.53 & 54.08 & 84.12 & 18.03 & 55.64 \\
\hline Cytology & 12.50 & 96.87 & 80.50 & 50 & 79.03 \\
\hline BTA + UBC & 74.07 & 97.97 & 95.09 & 90.90 & 94.35 \\
\hline BTA + TPS & 80.76 & 93.87 & 94.84 & 77.77 & 91.12 \\
\hline BTA + UBC + TPS & 84.61 & 100 & 96.07 & 100 & 96.77 \\
\hline
\end{tabular}

Since the value of a multi-biomarker profile in NMIBC diagnosis is insufficiently defined, we sought to explore the multi-biomarker panel based on BTA, UBC, and TPS. As shown in Table 2, the combined use of BTA with UBC and TPS increased the sensitivity of BTA from $76.92 \%$ to $84.61 \%$, specificity from $89.79 \%$ to $100 \%$ and accuracy from $91.03 \%$ to $96.77 \%$. Our data suggest that a three-biomarker panel (BTA+UBC+TPS) is better than a two-biomarker panel (BTA+UBC; BTA+TPS) or biomarkers alone (BTA, UBC, TPS) or routine urine cytology in assessment of primary NMIBC.

\section{Conclusions}

In comparison with cytology of voided urines, the analyzed biomarkers have some unique characteristics sacrificing specificity in favor of increased sensitivity. Our results indicated that the overall clinical sensitivity of the BTA was the highest of all assays, whereas that of cytology was the smallest one. On the other hand, BTA and cytology had the highest specificities with no significant differences between them. Moreover, our findings support the value of a multi-biomarker approach that incorporates BTA, UBC, and TPS to assess the primary NMIBC.

\section{References}

1. BRAY, F., FERLAY, J., SOERJOMATARAM, I., SIEGEL, R.L., TORRE, L.A., JEMAL, A., Global cancer statistics 2018: GLOBOCAN estimates of incidence and mortality worldwide for 36 cancers in 185 countries, CA Cancer J. Clin., 68, no. 6, 2018 , p. $394-424$.

2. TULIN, A., SLAVU, I., TULIN, R., ALECU, L., JECAN, R.C., ORLOV, C., IACIU, C.I., STANCULEANU, D.L., HAINAROSIE, R.,PITURU, S.,PANTEA STOIAN, A., STOIAN, A.,NITIPIR, C., Does sex of the patient play a role in survival for MSI colorectal cancer?, J. Mind Med. Sci., 5, no.1, 2018, p.101-108.

3. BOLOCAN, A., PADURARU, D.N., NITIPIR, C., HAINAROSIE, R., PITURU, S.M., DIACONU, C., SUCEVEANU, A., STOIAN, A.P., Mixed adenoneuroendocrine carcinoma of the gastrointestinal tract-features, diagnosis, management and prognostics, Rom. Biotech. Lett., 23, no.6, 2018, p.14193-14202.

4. NITIPIR, C., BARBU, M.A., ORLOV, C., STANCIU, A.E., POPA, A.M., HAINAROSIE, R., PITURU, S., ARSENE, A.L., PANTEA STOIAN, A.,Type II Diabetes Mellitus - Associated Risk Factor in the Onset and Evolution of Digestive Tract Carcinoma, Rom. Biotech. Lett., 24, no.1, 2019, p.140-146.

5. GINGHINA, O., BURCEA-DRAGOMIROIU, G.T.A., GALATEANU, B., HUDITA, A., DRAGOMIR, S., DRAGANESCU, D., BALANESCU, A., ROSCA, C.A., GIUGLEA, C., POPA, D.E., PANTEA-STOIAN, A., NEGREI, C., Long-term safety of biosimilar medicinal products - key for administration?, Farmacia, 67, no.1, 2019, p.18-26.

6. BABJUK, M., BURGER, M., COMPERAT, E., GONTERO, P., MOSTAFID, A.H., PALOU, J., VAN RHIJN B.W.G., ROUPRET, M., SHARIAT, S.F., SYLVESTER, R., ZIGEUNER, R., Guidelines Associates: CAPOUN, O., COHEN, D., HERNANDEZ, V., SOUKUP, V., EAU Guidelines on Non-muscle-invasive Bladder Cancer (TaT1and CIS). The 2018 update. https://uroweb.org/wp-content/uploads/EAU-Guidelines-onNon-muscle-Invasive-BC_TaT1-2017.pdf)

7. HOLMANG, S., HEDELIN, H., ANDERSTROM, C., HOLMBERG, E., BUSCH, C., JOHANSSON, S.L., Recurrence and progression in low grade papillary urothelial tumors, J. Urol., 162, no. 3 Pt 1, 1999, p. 702-707.

8. KOZIOROWSKI, J., STANCIU, A.E., GOMEZ-VALLEJO, V., LLOP, J., Radiolabeled Nanoparticles for Cancer Diagnosis and Therapy, Anticancer Agents Med. Chem., 17, no. 3, 2017, p. 333-354.

9. THOMAS, L., LEYH, H., MARBERGER, M., BOMABARDIERI, E., BASSI, P., PAGANO, F., PANSADORO, V., STERNBERG, C.N., BOCCON-GIBOD, L., RAVERY, V., LE GULUDEC, D., MEULEMANS, A., CONORT, P., ISHAK, L., Multicenter Trial of the Quantitative BTA TRAK Assay in the Detection of Bladder Cancer, Clin. Chem., 45, no. 4, 1999, p. 472-477.

10. BUDMAN, L.I., KASSOUF, W., STEINBERG, J.R., Biomarkers for detection and surveillance of bladder cancer, Can. Urol. Assoc. J., 2, no. 3, 2008, p. 212-221.

11. GLUCK, G., STOICA, R., NEAGOE, L., SINESCU, I., VESA, N., Rolul unor biomarkeri in monitorizarea recidivelor la pacientii cu cancer de vezica urinara, Revista Romana de Urologie, 4, 2009, p. 29-35.

12. LI, Y.P., JIA, X.P., JIANG, Y.Q., WANG, W., WANG, Y.L., WANG, X.L., GUO, Y.X., Differential expression of cytokeratin 14 and 18 in bladder cancer tumorigenesis, Exp. Biol. Med. (Maywood), 243, no. 4, 2018, p. 344-349. 
13. BABJUK, M., KOSTIROVA, M., MUDRA, K., PECHER, S., SMOLOVA, H., PECEN, L., IBRAHIM, Z., DVORACEK, J., JAROLIM, L., NOVAK, J., ZIMA, T., Qualitative and quantitative detection of urinary human complement factor H-related protein (BTA stat and BTA TRAK) and fragments of cytokeratins 8, 18 (UBC rapid and UBC IRMA) as markers for transitional cell carcinoma of the bladder, Eur. Urol., 41, no. 1, 2002, p. 34-39.

14. LU, P., CUI, J., CHEN, K., LU, Q., ZHANG, J., TAO, J., HAN, Z., ZHANG, W., SONG, R., GU, M., Diagnostic accuracy of the UBC $\circledast$ Rapid Test for bladder cancer: A meta-analysis, Oncol. Lett., 16, no. 3, 2018, p. 3770-3778.

15. BRIERLEY, J.D., GOSPODAROWICZ, M.K., WITTEKIND, C., editors, The TNM classification of malignant tumours. 8th Edition, Oxford: Wiley Blackwell; 2017. ISBN: 978-1-119-26357-9.

16. STANCIU, A.E., ZAMFIR-CHIRU-ANTON, A., STANCIU, M.M., POPESCU, C.R., GHEORGHE, D.C., Imbalance between Matrix Metalloproteinases and Tissue Inhibitors of Metalloproteinases Promotes Invasion and Metastasis of Head and Neck Squamous Cell Carcinoma, Clin. Lab., 63, no. 10, 2017, p. 1613-1620.

17. HALIM, A.B., EL-AHMADY, O., HAMZA, S., ABOUL-ELA, M., OEHR, P., Serum TPS versus TPA in Egyptian bladder cancer patients, Int. J. Biol. Markers, 8, no. 4, 1993, p. 221-226.

18. PRIOlO, G., GONTERO, P., MARTINASSO, G., MENCOZZI, G., FORMICONI, A., PELUCELLI, G., ZITELLA, A., CASETTA, G., VIBERTI, L., AIMO, G., TIZZANI, A., Bladder tumor antigen assay as compared to voided urine cytology in the diagnosis of bladder cancer, Clin. Chim. Acta, 305, no. 1-2, 2001, p. 47-53.

19. PICHLER, R., TULCHINER, G., FRITZ, J., SCHAEFER, G., HORNINGER, W., HEIDEGGER, I., Urinary UBC Rapid and NMP22 Test for Bladder Cancer Surveillance in Comparison to Urinary Cytology: Results from a Prospective Single-Center Study, Int. J. Med. Sci., 14, no. 9, 2017, p. 811-819.

20. STYRKE, J., HENRIKSSON, H., LJUNGBERG, B., HASAN, M., SILFVERBERG, I., EINARSSON, R., MALMSTROM, P.U., SHERIF, A., Evaluation of the diagnostic accuracy of UBC ${ }_{\circledast}$ Rapid in bladder cancer: a Swedish multicentre study, Scand. J. Urol., 51, no. 4, 2017, p. $293-300$.

Manuscript received: 23.05 .2019 